\title{
"Total Knee Arthroplasty in the Context of Severe and Morbid Obesity in Adults"
}

\author{
Luis M. Lozano $^{1}{ }_{*}$, Montserrat Núñez ${ }^{2}$, Sergi Sastre ${ }^{1}$ and Dragos Popescu ${ }^{1}$ \\ ${ }^{I}$ Knee Unit. Orthopaedic Department. Hospital Clínic. Universitat de Barcelona, Spain \\ ${ }^{2}$ Rheumatology Department, Hospital Clínic, August Pi i Sunyer Biomedical Research Institute. Barcelona, Spain
}

\begin{abstract}
Medical treatment for knee osteoarthritis proves insufficient in a considerable number of patients, who thus require surgical intervention, with arthroplasty being one of the most common procedures. The rate of knee replacement is consequently higher in the obese population. Obese patients who undergo knee arthroplasty face a larger number of associated comorbidities than do non-obese individuals, and this greater comorbidity can lead to more postoperative complications and worse outcomes. Given that obesity defined according to BMI would cover a large proportion of the population (a quarter of adults have a BMI $>30 \mathrm{~kg} / \mathrm{m}^{2}$ in some western societies) attention has focused on which subgroups might present the greatest problems. It appears that morbidly obese patients (BMI $>40 \mathrm{~kg} / \mathrm{m}^{2}$ ) are most at risk of complications. Some authors suggest the need to study more precise methods for component alignment in these patients. The use of an intramedullary guide made surgical intervention easier and was associated with a significantly shorter tourniquet time. Although the studies refer greater surgical difficulties on the basis of their BMI, the difficulty of surgery will ultimately depend on the morphology of the knee. The factors associated with a worse postoperative WOMAC score in severely and morbidly obese patients were the number of comorbidities, infrapatellar anthropometric index below percentile 75, greater intraoperative difficulty and the number of postoperative complications. When starting from a comparable preoperative status, severely and morbidly obese patients show a similar improvement than other patients.
\end{abstract}

Keywords: Morbid obesity, Obesity, Total knee arthroplasty.

\section{DEFINITION OF OBESITY}

In the past, weight was the sole measure used for classifying patients as obese [1]. However, the World Health Organization (WHO) has established a classification, accepted by all scientific groups, based on the relationship between weight and height [2] (Table 1). Body mass index (BMI) is given by the individual's weight divided by the square of their height, and on this basis the WHO classification includes four categories. Several recent papers establish groups for a BMI over $40 \mathrm{~kg} / \mathrm{m}^{2}$, although these are not officially recognized by the WHO. The term 'super morbid obese' is used for a BMI up to $50 \mathrm{~kg} / \mathrm{m}^{2}$, and 'super mega morbid obese' for a BMI over $60 \mathrm{~kg} / \mathrm{m}^{2}$.

\section{INCIDENCE OF OBESITY IN THE POPULATION}

Data published in 2003 by the International Association for the Study of Obesity (IASO) showed that in Spain 13.9\% of adult men and $15.1 \%$ of women were obese (BMI > $30 \mathrm{~kg} / \mathrm{m}^{2}$ ) [3]. In Catalonia, the ENCAT study published in 2007 used BMI to compare the incidence of overweight and obesity in the population [4]. The data showed that the proportion of obese men had increased from $9.9 \%$ in 1992-3 to $16.6 \%$ in $2002-03$, whereas the rate for women remained stable over the same period of time (15.0\% in 1992-3 and $15.2 \%$ in 2002-03). Data for other European countries show that in England, in 2007, 23.6\% of men and 24.4\% of

*Address correspondence to this author at the Hospital Clínic. c/Villarroel 170. 08036 Barcelona. Spain. Tel: 34932275400; Fax: 34932279871;

E-mails: Skytrauma@hotmail.com, LLozano@clinic.ub.es,
Table 1. Classification of Obesity According to the World Health Organization (WHO)

\begin{tabular}{|c|c|}
\hline BMI & Category \\
\hline \hline $25-29,99 \mathrm{~kg} / \mathrm{m}^{2}$ & Overweight. Class 0 \\
\hline $30-34,99 \mathrm{~kg} / \mathrm{m}^{2}$ & Obesity. Class I \\
\hline $35-39.99 \mathrm{~kg} / \mathrm{m}^{2}$ & Severe obesity Class II \\
\hline$>40 \mathrm{~kg} / \mathrm{m}^{2}$ & Morbid obesity. Class III \\
\hline
\end{tabular}

women were obese, whereas the corresponding figures for France were $16.1 \%$ and $17.6 \%$ respectively (data for 2006), and for Germany $20.5 \%$ and $21 \%$ (data from 2003) [3]. In Canada the proportion of the population who are obese has risen from 14\% in the 1980s to $23 \%$ in 2007 (men 22.9\%; women 23.2\%). Data from 2003-4 for the US show that $31.1 \%$ of adult men and $33.2 \%$ of women were obese (BMI $\left.>30 \mathrm{~kg} / \mathrm{m}^{2}\right)$ [3].

\section{RELATIONSHIP BETWEEN OBESITY AND KNEE OSTEOARTHRITIS}

Several reports have demonstrated the relationship between obesity and the development of degenerative disease in the knee [5-7].

\subsection{Risk of Osteoarthritis in Obese Patients}

Obese patients have an estimated risk of between 9-13\% of developing osteoarthritis (OA) of the knee for each additional kilo of body mass. With each $5 \mathrm{~kg}$ of weight gain, their risk of developing osteoarthritis increases by $35 \%$ [6]. 
According to the US National Health and Nutrition Examination Survey, adults with a BMI over $30 \mathrm{~kg} / \mathrm{m}^{2}$ are four times more likely to present radiographic signs of knee osteoarthritis than adults with BMI below this figure [7].

Signs of knee osteoarthritis in radiographic studies, in association with clinical symptoms of knee osteoarthritis in obese elderly men and women appeared a mean of 37 years earlier than in their non-obese. The association of overweight and knee osteoarthritis is stronger in women than in men. Fifty per cent of middle-aged obese healthy women with unilateral radiographically demonstrated knee OA developed osteoarthritis in the contralateral knee within two years, a 5-fold higher incidence than non-obese women in the same age range $[5,7]$.

Obesity is also related to the progression of osteoarthritis. More severe forms of radiological osteoarthritis are found in patients with already established osteoarthritis who gain weight [8].

It has not been clearly established how excess weight causes the degeneration of joint cartilage. As in cardiovascular disease and diabetes, the risk of developing knee osteoarthritis increases with BMI, but there does not seem to be a relationship with the patient's morphotype - as there is between central or truncal obesity and the diseases mentioned $[9,10]$.

\subsection{Theories of the Relationship Between Obesity and Osteoarthritis}

The degeneration may occur through various mechanisms. Biomechanical, imaging, histological and analytical studies have shown that cartilage volume loss in obese patients is greater and occurs more quickly than in the non-obese population, and that the higher the degree of obesity, the faster and more profound the deterioration [11].

\subsubsection{Biomechanics and Knee Osteoarthritis}

From the biomechanical perspective, obesity causes a repeated application of axial forces on the surface of the joint, damaging the articular cartilage and leading to subchondral bone sclerosis. Magnetic resonance imaging (MRI) studies show that the main effects of the increase in BMI are the appearance of defects in the joint cartilage and an increase in the size of the tibia due to the formation of osteophytes [12].

The presence of glycosaminoglycans (GAG) in joint cartilage increases when there are compressive forces, in response to the damage caused. When the GAG content is studied as a measure of chondrocyte activity and of the progress of osteoarthritis in the knee, there is a significant correlation between increased glycosaminoglycan levels and patients' BMI [13].

In the weight-bearing joints, such as the knee, the axial load is the cause of deterioration, especially in knees presenting major varus malalignment, in which the excess load on the internal compartment alters chondrocyte biosynthesis. In joints that do not support axial load, for example the hands, this mechanism is not involved [14].

MR imaging studies have shown that the increase in fat mass reduces volume and increases cartilage defects, while an increase in fat-free mass (total body weight without fat or muscle mass) increases knee cartilage volume [14]. This suggests that there may be other reasons for the development of knee osteoarthritis in addition to biomechanical causes.

Other authors suggest that excess fat may lead to an irregular growth of joint cartilage and may inhibit cartilage repair mechanisms [15-17].

\subsubsection{Hormonal Influence on the Development of Knee Osteoarthritis}

Several studies have linked the obesity gene (ob) and the hormone it produces, leptin, with the deterioration of joint cartilage [15-20]. Both experimental and clinical trials have shown significant levels of this hormone in chondrocytes of obese patients developing osteoarthritis, whereas it is virtually nonexistent in chondrocytes from patients who did not develop OA. Leptin is synthesized in osteoblasts and chondrocytes as well as in adipocytes [15]. Receptors for this hormone have been found in joint cartilage. Systemic variations in leptin levels regulate the proliferation of the chondrocytes and the anabolic function, producing osteophyte formation during osteoarthritis [17].

Studies by various authors have found that leptin levels in joint cartilage increase in line with the patient's BMI [16, 19] and significant levels of this hormone have been found in the osteophytes and the chondrocytes of the joint cartilage of people with OA, whereas in healthy subjects chondrocytes that produce leptin are few [15].

Further evidence of the role of leptin in the development of osteoarthritis is the prevalence of knee osteoarthritis in women [17]. As women have more body fat, the production of this hormone is higher in women than in men and its level in blood is also higher. This is also the case in pre-pubertal females, so high levels of leptin in the blood may influence the development of cartilage and predispose to degenerative changes in adulthood. Weight reduction in obese patients suffering from osteoarthritis decreases in blood leptin levels, correlating with improved symptoms [16].

A relationship has been found between reduction in knee cartilage volume with blood leptin levels in obese female adults. In focal defects of the cartilage this relationship was not found, indicating that these defects may be related more to non-hormonal factors [18].

Leptin contributes to the abnormal functioning of osteoblasts in osteoarthritic knees, causing the proliferation of various cytokines that damage the cartilage [21].

\section{TREATMENT OF KNEE OSTEOARTHRITIS IN THE OBESE PATIENT}

\subsection{Weight Loss}

According to the Framingham study [5] women who reduce their BMI by two units reduce the likelihood of developing OA by over 50\%. Exercise combined with a dietary programme designed to produce weight loss can improve the functionality and symptomatology of obese patients with gonarthrosis [5-7, 22-25]. Messier [23] found that a $5 \%$ reduction in a patient's weight over an eighteenmonth period led to an $18 \%$ improvement in the patient's functionality. When weight loss was linked to an exercise programme, function improved by $24 \%$ and was 
accompanied by a significant improvement in mobility. In terms of functional outcomes, measured by means of the Western Ontario and McMasters Universities Osteoarthritis Index (WOMAC), research has shown that in overweight women with knee pain due to osteoarthritis a $7 \mathrm{~kg}$ weight reduction over a period of six months led to a significant change in WOMAC ratings for pain (46\% reduction) and function (38\% improvement) [26]. A population-based case control study carried out in England by Coggon [27] concluded that if all overweight or obese people reduced their weight by $5 \mathrm{~kg}$ or until their BMI was within the normal recommended range, $24 \%$ of surgical interventions for knee osteoarthritis might be avoided.

\subsection{Total Knee Arthroplasty}

Medical treatment for knee osteoarthritis proves insufficient in a considerable number of patients. Among surgical interventions, arthroplasty is one of the most common procedures. The rate of knee replacement is higher in the obese population. As noted above, the proportion of obese individuals in Canada has risen from 14\% twenty-five years ago to $23 \%$ in 2007 [28]. Concomitantly, the number of knee and hip replacements performed rose by $87 \%$ over the ten years from $1993 / 4$ to $2003 / 2004$. If normal weight patients are used as a baseline with respect to the need for intervention in the form of arthroplasty (RR 1.00), it can be seen that as BMI increases so does the likelihood of the need for joint replacement. In patients with class III (morbid) obesity the risk is more than 30 times higher. In the UK a study known as the 'Million Women Study' prospectively followed a cohort of 1.3 million women aged 50-64 years recruited between 1996 and 2001, in order to ascertain the risk of requiring a hip or knee replacement on the basis of BMI [29]. The authors report a RR of $69 \%$ in middle-aged women with a BMI $\geq 25 \mathrm{~kg} / \mathrm{m}^{2}$. Furthermore, analysis of the relative risk of requiring surgical intervention according to the different categories of obesity in these women showed that the risk rose exponentially with increasing BMI. Another study in the UK examined the age at which patients with gonarthrosis undergo surgery in relation to their BMI at the time of the operation [30], and found a statistically significant relationship between BMI and age at the time of surgery $(p<0.001)$ : morbidly obese patients underwent surgery 13 years earlier than normal weight individuals. In a study of the BMI of patients undergoing hip and knee replacement surgery over the period 1990-2005 in a specialist clinic in North Carolina (US), Fehring [31] found that $10.5 \%$ of surgical patients in 1990 were morbidly obese, $8.3 \%$ in $1995,10.3 \%$ in 2000 and $17.1 \%$ in 2005 .

\section{THE OBESE PATIENT AND TOTAL KNEE ARTHROPLASTY}

Given the anatomical difficulties related to the airway, pharmacokinetic changes, and the risk of cardiorespiratory complications, regional anaesthesia has certain advantages over general anaesthesia in these patients [32]. It requires only minimal manipulation of the airway, avoids the need for anaesthetic drugs that induce cardiopulmonary depression, reduces postoperative nausea and vomiting, and enables better control of postoperative pain. This means that lower doses of postoperative opiates are required, something which is of vital importance in these patients, who are at greater risk of postoperative respiratory complications. However, peripheral nerve blocking techniques are more difficult to perform than in the general population [32], and the rate of failed blocks increases in line with BMI. In the event of a failed nerve block, general anaesthesia is often required, with the risks that this implies. Performing neuroaxial blocks also presents certain technical challenges, since it is more difficult to locate anatomical reference points and more puncture attempts are required to achieve the block. Compared to the general population, obese patients require lower doses of local anaesthesia to achieve the same degree of epidural or intradural block, and they are more likely to present cephalic migration of the local anaesthetic. In the case of intradural anaesthesia this can be explained by the fact that these patients have a smaller volume of cerebrospinal fluid. Given the anatomical difficulties associated with obese patients the use of ultrasound to guide the techniques of local or regional anaesthesia is recommended, since this increases the rate of successful peripheral blocks.

Obese patients present a reduced immune response. This is because obesity is associated with insulin resistance and hyperglycaemia, which reduce leukocyte function. This situation may even arise in obese patients who are not diagnosed with diabetes. At all events, their pharmacokinetic status is altered due to changes in renal clearance, in liver metabolism and in the distribution volume. Obesity also involves an increased adipose tissue mass, which affects any medication with lipophilic properties. Likewise, hydrophilic drugs may be affected by the increase in organic mass, in free fat mass and in blood volume that characterize obesity. These changes affect both intravenous anaesthesia and antibiotics. Indeed, the usual dose of prophylactic antibiotics may be insufficient in these patients, who by their very nature already present a higher incidence of postoperative infection. It is therefore advisable to tailor the dosage to the individual patient and to monitor the antibiotic dose in the event of infections that require prolonged treatment with intravenous antibiotics [33].

\subsection{Associated Comorbidities in the Obese Patient}

Obese patients who undergo knee arthroplasty face a larger number of associated comorbidities than non-obese individuals, and this greater comorbidity can lead to more postoperative complications and worse outcomes. In one study of patients undergoing knee arthroplasty Miric [34] found a significantly higher rate of associated comorbidities among obese patients, with a prior medical history $(\mathrm{p}<0.0001)$, a history of cardiac problems $(\mathrm{p}<0.02)$ and diabetes mellitus $(\mathrm{p}<0.006)$ all being more common in obese individuals. A more detailed analysis revealed that the greatest difference was observed among patients in obesity class II (BMI $\left.>35 \mathrm{~kg} / \mathrm{m}^{2}\right)$. In another study of comorbidities, Namba [35] reviewed 1813 hip and knee replacement operations carried out in eleven hospitals in the US, and found that the group of patients with a BMI above $35 \mathrm{~kg} / \mathrm{m}^{2}$ spent longer in hospital and had a higher rate of infections. Although severely and morbidly obese patients had a significantly higher rate of diabetes most of the patients who suffered an infection were not diabetic. In 2010 Nuñez [36] studied a population of morbidly obese patients who had undergone total knee arthroplasty, comparing them with a 
control group. The number of associated comorbidities was higher in the obese patients, and their presence had an effect on the functional outcome of these patients at one-year follow-up, as measured by the WOMAC.

\subsection{Complications Associated with Knee Replacement Surgery in Obese Patients}

In 2006 Gillespie [1] published a review of obesity and knee arthroplasty in the UK, in light of the debate that arose following the decision to exclude obese individuals from waiting lists for total knee arthroplasty (TKA). This decision proved highly controversial given the large numbers of obese patients and the incidence of gonarthrosis among them, with the corresponding need for TKA. Recent research has also analysed the profile of the obese patient who is most likely to face problems during and after TKA. Given that obesity defined according to BMI would cover a large proportion of the population (a quarter of adults have a BMI $>30 \mathrm{~kg} / \mathrm{m}^{2}$ in some western societies) attention has focused on which subgroups might present the greatest problems. It appears that morbidly obese patients (BMI $>40 \mathrm{~kg} / \mathrm{m}^{2}$ ) are most at risk of complications. In 1998 Winiarsky [37] published a paper that warned of the risks of TKA in this group of patients. In this study of 40 morbidly obese patients who underwent TKA, $22 \%$ presented problems with wound healing, $10 \%$ developed infection and $8 \%$ had an avulsion, from the tibial insertion, of the medial collateral ligament during surgery. Most of the infections were related with early wound complications. Winiarsky attributed the complications to difficulties faced during surgery due to the special characteristics of the knee in these morbidly obese patients. Specifically, he noted that their knees are more difficult to access surgically and that it is harder to visualize the surgical field, adding that it is also more difficult to position the tibial cutting block using an extramedullary guide, which may be the cause of a varus tibial cut.

Krushell [38] compared the outcomes of 39 TKA in morbidly obese patients and non-obese controls. In the morbidly obese the components were more likely to be aligned in a more varus position. In all the procedures an intramedullary guide was used to position the femoral cutting block and an extramedullary guide for the tibial block. The femoral component showed a $5^{\circ}$ valgus alignment in the morbidly obese group, compared with a mean of $6.5^{\circ}$ valgus alignment among controls $(\mathrm{p}<0.05)$; the alignment of the tibial component was $2.5^{\circ}$ varus and $1.0^{\circ}$ varus respectively $(\mathrm{p}<0.05)$. Among their conclusions the authors suggest the need to study more precise methods for component alignment in these patients. In 2008 our group published a study [39] that compared the use of intramedullary and extramedullary guides in 70 severely and morbidly obese patients, finding that the use of an intramedullary guide made surgical intervention easier and was associated with a significantly shorter tourniquet time.

Although the studies referred to above identify those patients who may pose greater surgical difficulties on the basis of their BMI, the difficulty of surgery will ultimately depend on the morphology of the knee. In 2008 our group [40] conducted an anthropometric study of the knees of severely and morbidly obese patients who were due to undergo TKA. Specifically, we determined a number of

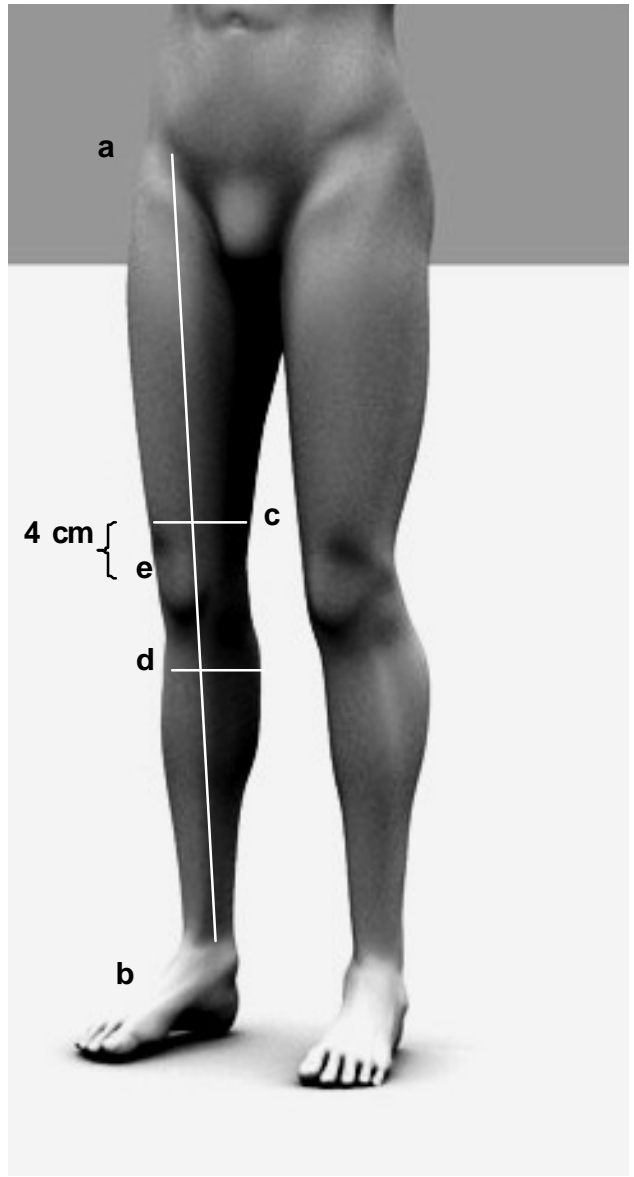

Fig. (1). Reference points in the target extremity to be taken into account when calculating the anthropometric indices of the knee.

indices that might have prognostic value in relation to surgical difficulty and which could affect the outcomes of arthroplasty. These indices were calculated by relating the length of the extremity to be operated on with the circumference of the knee, measured at two levels: above the upper pole of the patella and at the level of the anterior tibial tuberosity (Fig. 1). A suprapatellar index below 1.6 was associated with greater surgical difficulty. However, no relationship was found between surgical difficulty and patients' BMI. An index below 1.6 corresponds to a wide knee with thicker subcutaneous cell tissue. In this same group of obese patients a relationship was found between anthropometric knee data and the functional outcomes of knee arthroplasty [41]. An infrapatellar index below 1.75 was associated with poorer functional outcomes and more pain one year after the TKA. In a series of 127 severely and morbidly obese patients who underwent TKA at the Hospital Clinic in Barcelona the rate of surgical re-intervention within the first year was $13.4 \%$. The majority of these cases were due to early infections $(7 \%)$ and anterior knee pain $(2.4 \%)$; the others were the result of rupture of the extensor apparatus or early loosening (4\%).

\subsection{Infection in Total Knee Arthroplasty in Obese Patients}

In a study based on a series of 1813 total hip or knee replacement patients who underwent surgery in California 
between 2001 and 2002, Namba [35] drew attention to the high rate of infection following arthroplasty in patients with a BMI $>35 \mathrm{~kg} / \mathrm{m}^{2}$. In this series $23 \%$ of patients $(422 / 1813)$ had a BMI $>35 \mathrm{~kg} / \mathrm{m}^{2}$, and their risk of infection (odds ratio) was 6.7-fold higher. These figures are in line with the previously mentioned results of Winiarsky [37] in a group of morbidly obese patients. Namba [35] attributed the greater risk of infection to the difficulty of exposing the surgical field, the longer duration of surgery, the poor vascularization of fatty tissue and the reduced immune response found in obese individuals. The rate of diabetes mellitus in the severely and morbidly obese patients in this series was significantly high, although only one of the six cases of infection occurred in a diabetic patient. Even in the absence of diabetes, obesity is associated with insulin resistance and hyperglycaemia, conditions which contribute to poor leukocyte function. The syndrome characterized by truncal obesity, a sedentary lifestyle and insulin resistance is known as 'metabolic syndrome' or ' $\mathrm{X}$ syndrome'.

Various studies have examined large series of TKA in the search for risk factors for infection and other complications, and several regression analyses have shown that obesity, specifically a BMI over $40 \mathrm{~kg} / \mathrm{m}^{2}$, is associated with a greater risk of infection. In a retrospective study conducted by Patel [42] in 2007 of the factors that predisposed toward implant infection in 1226 arthroplasties, obesity was the only independent factor associated with the risk of infection. In a 2008 study of 1509 knee replacement operations, Chesney [43] found that diabetes and a BMI > $40 \mathrm{~kg} / \mathrm{m}^{2}$ were associated with higher rates of implant infection. Also in 2008 Pulido [44] carried out a prospective study of 9245 patients who underwent total hip or total knee replacement in order to examine the factors associated with joint infection. The results of the multivariate logistic regression analysis showed that morbid obesity, among other factors, predisposed towards this infection (OR $3.23 ; \mathrm{p}<0.001)$. In 2009 Bordini [45] studied 9735 knee prostheses implanted in 8892 patients between 2000 and 2005 recorded on a database in the Italian region of Emilia-Romagna. Of the 9735 implants, 186 required early revision, 58 due to sepsis. Regression analyses revealed no relationship between BMI and the presence of complications or early implant failure, nor with the presence of implant infection or the length of hospital stay. The study included 172 morbidly obese patients (BMI > $40 \mathrm{~kg} / \mathrm{m}^{2}$ ). Also in 2009 Jämsen [46] analysed 2647 consecutive knee arthroplasties performed in Finland and found that prosthetic joint infection was related with complex surgery, associated comorbidity and obesity. In the same year a study by Dowsey [47] of 1214 TKA carried out in Australia found that the factors associated with prosthetic infection were morbid obesity (OR 8.96) and diabetes (OR 6.87). The cases of infection in diabetic patients were associated with obesity. Finally, Malinzak [48], also in 2009, published a retrospective review of 8494 hip and knee arthroplasties and found that a BMI above 50 $\mathrm{kg} / \mathrm{m}^{2}$ increased the risk of suffering a deep infection by an odds ratio of $21.3(\mathrm{p}<0.0001)$.

\subsection{Clinical and Functional Outcomes of Total Knee Arthroplasty in Obese Patients}

The literature regarding functional outcomes in obese patients undergoing arthroplasty has produced disparate findings [37, 38, 49-54]. Given that some studies compare obese and non-obese individuals without discriminating between the various BMI categories it is necessary to examine each series individually in order to determine whether the data are actually comparable. Furthermore, the results vary depending on the type of obese population studied and the type of study. Specifically, those series with a greater number of morbidly obese patients report worse clinical and functional outcomes in comparison to non-obese patients. For example, Winiarsky ([37] found significantly worse $(p<0.00005)$ outcomes after TKA in morbidly obese patients compared to the other categories of patients. In two studies published in 2004, Foran [52, 53] compared TKA outcomes in a population of obese and non-obese patients. In the first study [52] the authors analysed 78 TKA performed in obese patients over a seven-year period and found that this group had worse functional outcomes (measured according to the Knee Society score) than non-obese controls. The worst outcomes of all were found in the subgroup of morbidly obese patients. It should be noted that in this series the obese and non-obese patients had a similar preoperative clinical and functional status, with no significant differences in Knee Society objective and functional scores. However, the non-obese patients showed significantly better postoperative objective scores, and there was also a significant difference in the mean change in objective knee score. In the second study [53] the authors conducted a 15year follow-up of 30 non-cemented knee implants in matched case and control groups with no preoperative differences in functional status. At the end of follow-up the non-obese patients had a better Knee Society objective score (89 vs. 81 in obese patients). Stickles [49] in 2001 and Rajgopal [54] in 2007 analysed outcomes in obese patients undergoing total joint arthroplasty according to scores on the WOMAC. Both studies considered not only absolute outcomes but also the postoperative change in score. Stickles [49] found an inverse relationship between BMI and WOMAC scores at one-year follow-up, although there were no significant differences between pre- and postoperative scores; preoperative WOMAC scores were lower with higher BMI, and postoperative outcomes were also worse with higher BMI. These results were corroborated by Rajgopal [54] in a Canadian study that divided patients into morbidly obese $(n=69)$ and non-morbidly obese $(n=481)$. Although the morbidly obese patients had lower postoperative WOMAC scores, their changes in score were comparable to those of the non-morbidly obese patients.

Two studies by Núñez, in 2007 [55] and 2009 [56], analysed the factors associated with worse functional outcomes following total knee arthroplasty. Follow-up over three and seven years showed that WOMAC scores, especially on the pain scale, were worse among severely obese patients (BMI $>35 \mathrm{~kg} / \mathrm{m}^{2}$ ) than in with non-obese individuals. WOMAC scores were also worse in patients who presented postoperative complications. The factors associated with a worse postoperative WOMAC score in severely and morbidly obese patients were the number of comorbidities, infrapatellar anthropometric index below percentile 75, greater intraoperative difficulty and the number of postoperative complications. Postoperative pain at one year was associated with an infrapatellar anthropometric index below percentile 75 , greater surgical difficulty and a 


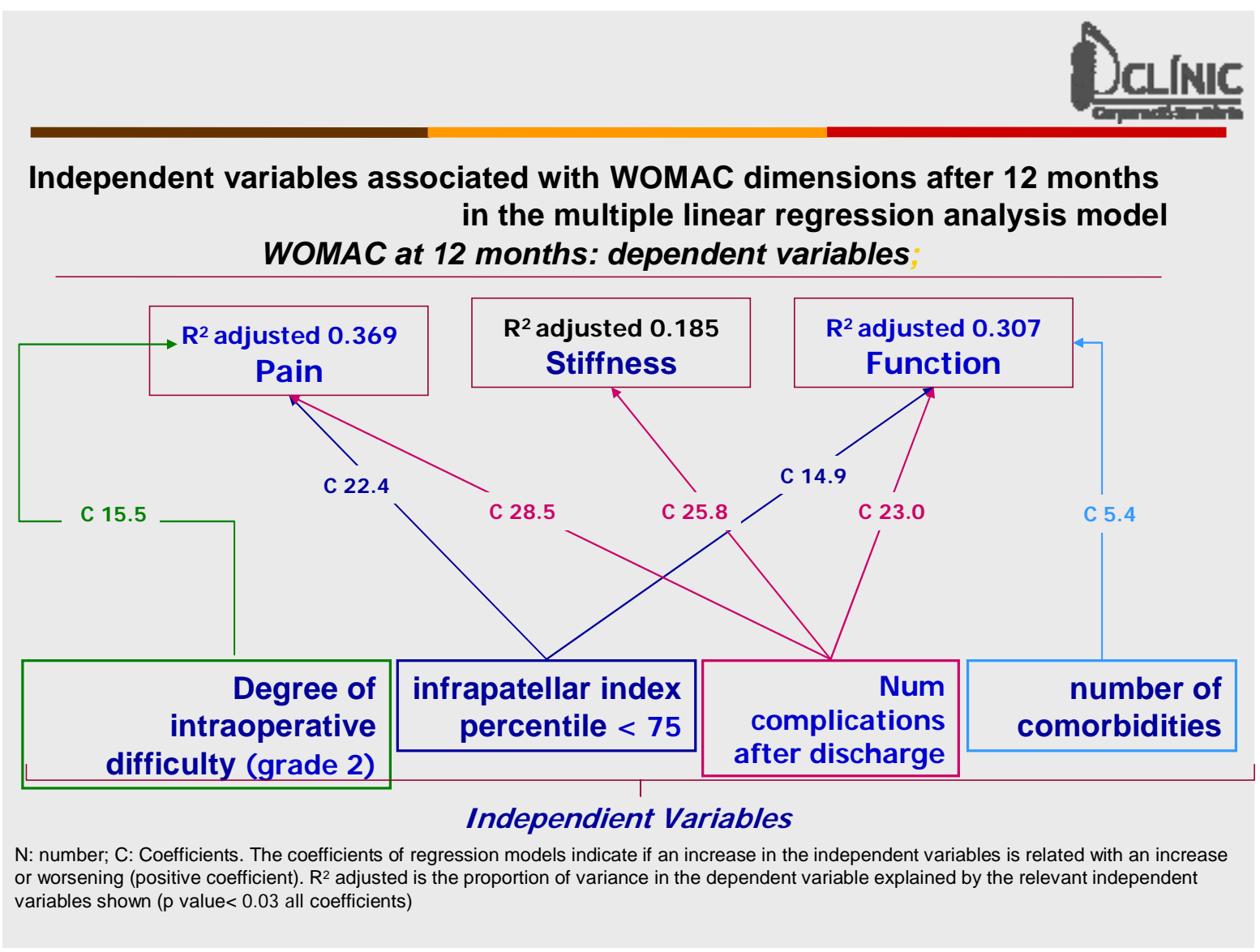

Fig. (2). Influence of knee anthropometric data, surgical difficulty, complications and comorbidities on total knee arthroplasty outcomes, measured according to the WOMAC.

greater number of postoperative complications (Fig. 2). The aim of another study by our group at the Hospital Clinic in Barcelona was to compare the health-related quality of life (HRQOL) preoperatively and at one-year follow-up in severely and morbidly obese patients undergoing total knee arthroplasty [41]. These patients had similar preoperative WOMAC scores, the only difference being in their BMI. Both groups of patients showed significantly improved WOMAC scores after surgery. Obese patients presented a significantly greater intraoperative challenge and more postoperative complications, although there were no differences in WOMAC scores at one-year follow-up. We concluded that when starting from a comparable preoperative status, the improvement achieved in severely and morbidly obese patients is similar to that recorded in other patients.

\subsection{Survival of Prosthetic Implants}

Most authors define implant survival as the period during which there is no need for revision surgery (due to poor clinical outcomes, loosening and/or infection), with the endpoint of survival being the removal or replacement of the prosthetic components. In all cases survival analyses are based on Kaplan-Meier curves. Spicer [50] found no differences between obese and non-obese patients as regards the need for implant replacement. Specifically, survivorship analyses revealed no differences between obese $(98.1 \%)$ and non-obese patients $(99.9 \%)$ at either six or ten years $(97.2 \%$ and $95.5 \%$ respectively). In a study published in 2003 Vázquez-Vela [57] reported that ten-year implant survival rates were influenced by sex, age and BMI; whereas the overall ten-year survival rate was $97 \%$, the figures for obese and non-obese patients separately were $92.7 \%$ and $98.5 \%$ respectively $(\mathrm{p}=0.0015)$. Furthermore, the survival rate among the youngest patients ( $<60$ years) was only $59.5 \%$ in obese patients (compared with $88.6 \%$ in non-obese individuals), while among males in this age group the tenyear survival rate was only 35.7\%. In 2004 Foran [52] reported that the survival (need for revision surgery) of cemented implants was lower in obese patients after 60-80 months of follow-up. In another paper, the same authors [53] studied survival rates for non-cemented knee implants, reporting that the rates fell among obese patients after 14 years. The survival studies carried out by Jackson [58] in 2009 found no significant difference between obese and nonobese patients (96.4\% vs. $98 \%$ respectively). Recent studies based on finite element analysis have examined the excess load borne by the tibial component in severely and morbidly obese patients. The addition of a tibial rod which increases the area of contact and transfers the load to the metaphysis area can reduce the excess load on the tibial plate and prevent early loosening. The use of trabecular metal tibial base plates to ensure early anchoring of the tibial component to the bone is another interesting line of work.

\subsection{Weight Variation Following Total Knee Arthroplasty}

As noted by various authors, the reduced physical activity of patients following a TKA means that no weight loss occurs. The belief that obese patients with OA carry 


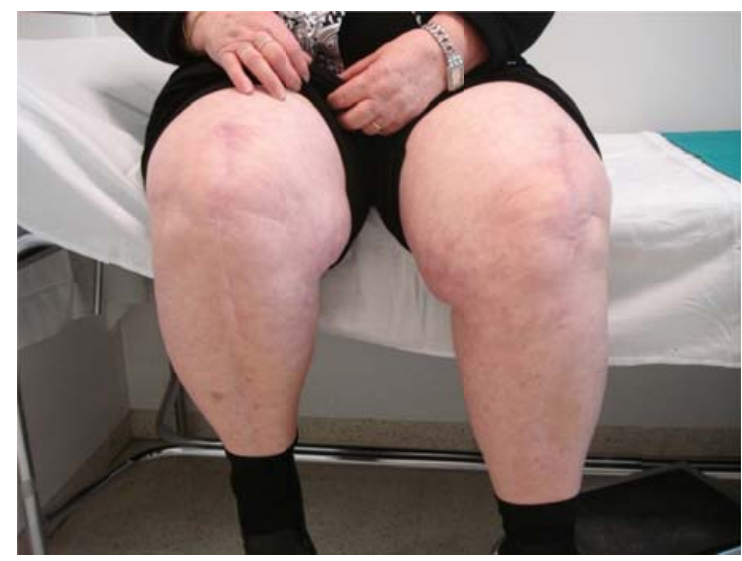

Fig. (3). Morphology of the knee in a morbidly obese patient.

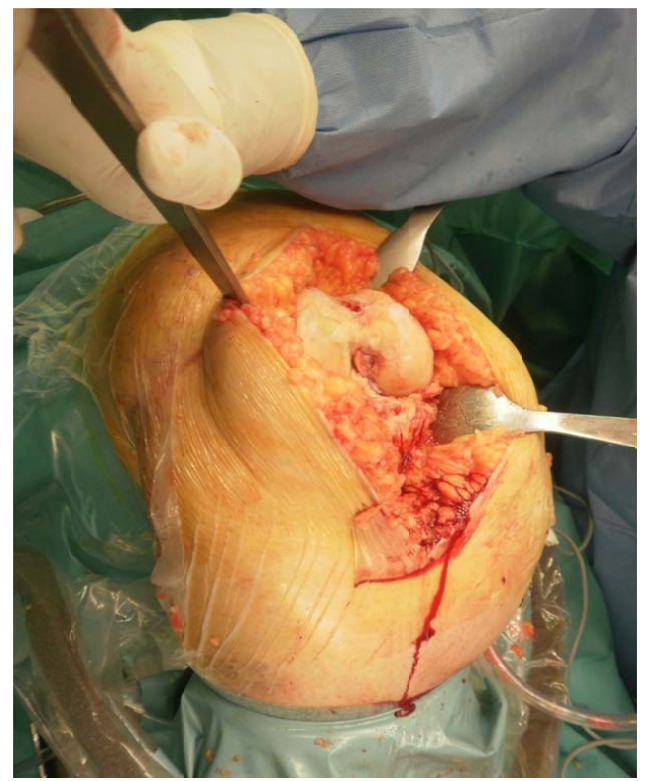

Fig. (4). Clinical image of the surgical field in the knee of a morbidly obese patient.

excess weight because their physical activity is limited by their joint pain is not borne out by research. A study by Booth [59] in 2002 found that only $18 \%$ of obese patients lost weight after a TKA. In a prospective study of 100 patients who underwent hip or knee replacement surgery published in 2005, Heisel [60] found that both groups gained weight after the arthroplasty, and that the youngest patient group presented the greatest weight gain. These findings suggest that obesity should be treated as an independent disease that is unrelated to the inactivity of patients with osteoarthritis. In 2008 Lachiewicz [61] analysed weight and activity change in 188 overweight and obese patients in the two years following their total knee arthroplasty, finding that at two-year follow-up, $17 \%$ had lost weight ( $>5 \%$ body weight), $60 \%$ weighed the same and $23 \%$ were heavier than they were prior to the operation. These differences were not statistically significant. BMI increased by $0.46 \mathrm{~kg} / \mathrm{m}^{2}$ with respect to preoperative levels $(\mathrm{p}=0.049)$, although the authors note that this increase may have been due to the height loss presented by $39 \%$ of patients at two-year followup, rather than to an actual weight gain. Activity increased with respect to preoperative levels $(p<0.001)$, even though the patients did not achieve any significant weight loss. In

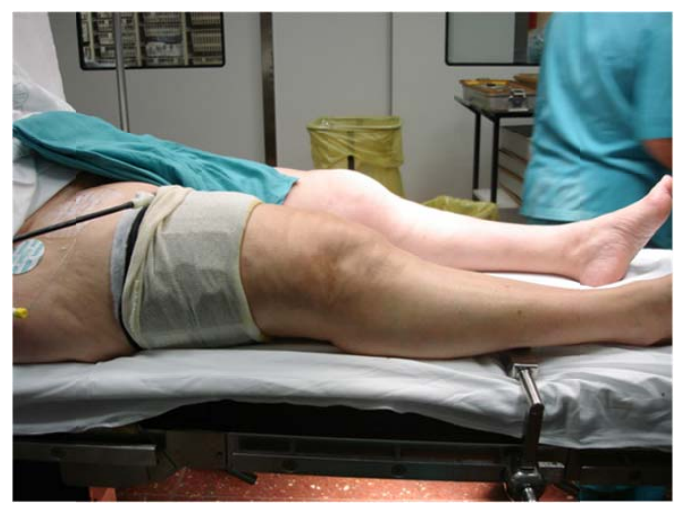

Fig. (5). Low pressure tapered tourniquet cuff fitted to the thigh of a morbidly obese patient.

2010 Dowsey [62] reported a series in which $12.6 \%$ of obese patients who underwent a TKA presented a weight loss of at least $5 \%$ of body weight, although $21 \%$ gained weight after the intervention.

\subsection{Prophylaxis of Thromboembolic Disease}

The standard doses of low molecular weight heparin (LMWH) may also be insufficient in obese patients. Although several recent studies have highlighted this problem there are currently no clear, weight-adjusted guidelines for the prophylactic treatment of deep vein thrombosis (DVT). Recent recommendations for the use of enoxaparin in morbidly obese patients suggest a dose of 40 mg every 12 hours or $60 \mathrm{mg}$ every 24 hours. Fondaparinux at a dose of $2.5 \mathrm{mg} /$ day has been shown to be more effective than LMWH in the prophylaxis of DVT in obese patients [63].

New oral anticoagulants such as rivaroxaban in a single daily dose of $10 \mathrm{mg}$ offer a safe and effective alternative in these patients, as there is no need to adjust the dose according to weight and the drug is correctly absorbed when administered orally. This route of administration also improves treatment adherence in this group of patients.

\section{PERFORMING KNEE REPLACEMENT SURGERY IN SEVERELY AND MORBIDLY OBESE PATIENTS}

Since 2005, the knee prosthetic surgery unit at the Hospital Clinic in Barcelona has included a team of surgeons whose work focuses on the treatment of severely and morbidly obese individuals. To date, this team has operated on 500 patients with a $\mathrm{BMI}>35 \mathrm{~kg} / \mathrm{m}^{2}$. As this literature review suggests, these patients pose a greater surgical challenge and present more postoperative complications, factors which influence both functional outcomes and the pain experienced after surgery. In our view, obese patients should be informed of the greater risks associated with their surgery; indeed, this point is included in our informed consent procedure. In order to detect which of our severely and morbidly obese patients will pose the greatest surgical challenge and present the worst outcomes we determine the anthropometric indices mentioned above (Fig. 1). If the results indicate a poor prognosis we adapt our surgical technique (Figs. 3 and 4), using intramedullary tibial cutting guides, low pressure tapered tourniquet cuffs which are easier to fit to the patient's thigh (Fig. 5), and devices that enable the leg to be held in different degrees of flexion 


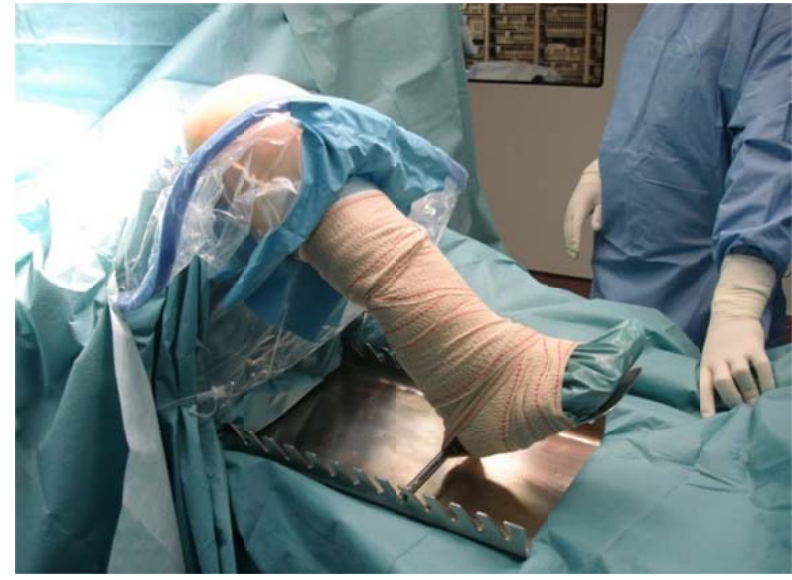

Fig. (6). Use of a slotted-base leg positioner to assist the surgical procedure.

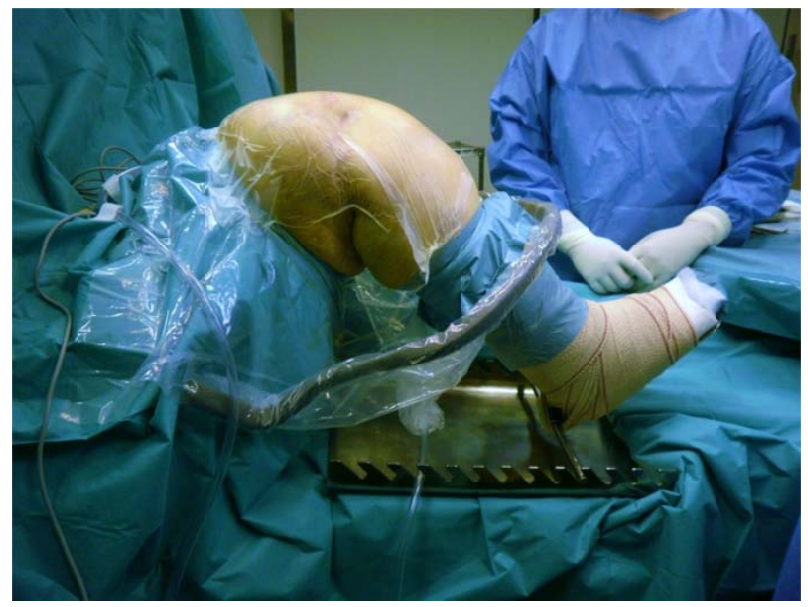

Fig. (7). The knee as it appears when using the slotted-base leg positioner. The device enables different degrees of flexion and extension to be achieved.

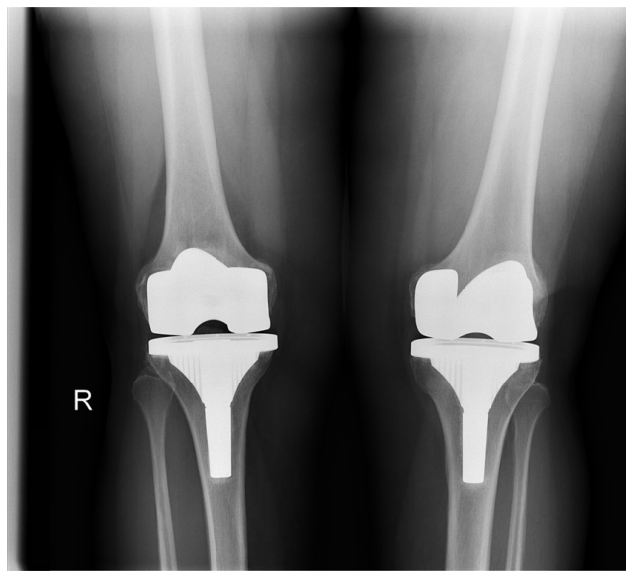

Fig. (8). Frontal radiograph of an implant with tibial rod.

(slotted-base leg positioner; see Figs. 6 and 7). In these patients we also use implant models that ensure minimal constriction - either posterior stabilized implants or, in the event of instability or extreme axial deviation, rotating hinge prostheses. In order to prolong the survival of the tibial implant we use short tibial rods $(45-50 \mathrm{~mm})$ which increase the area of contact and reduce the load of the bone under the tibial plate (Fig. 8); more recently, we have introduced trabecular metal tibial components that provide early anchoring of the tibial implant to the bone (Figs. 9 and 10).

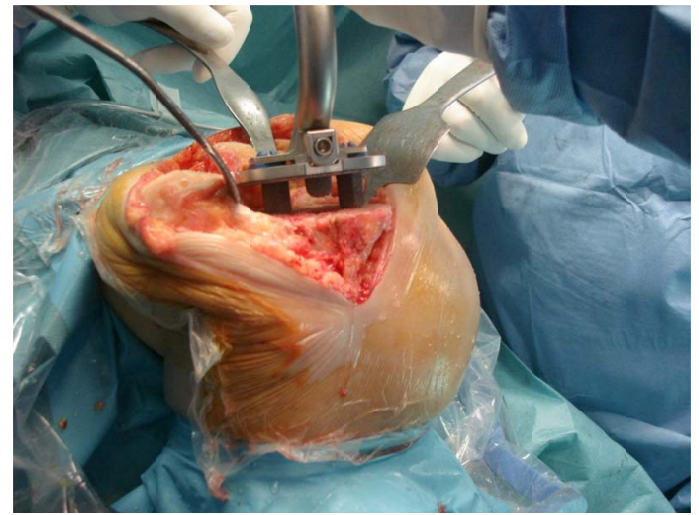

Fig. (9). The moment of implanting a trabecular metal tibial component.

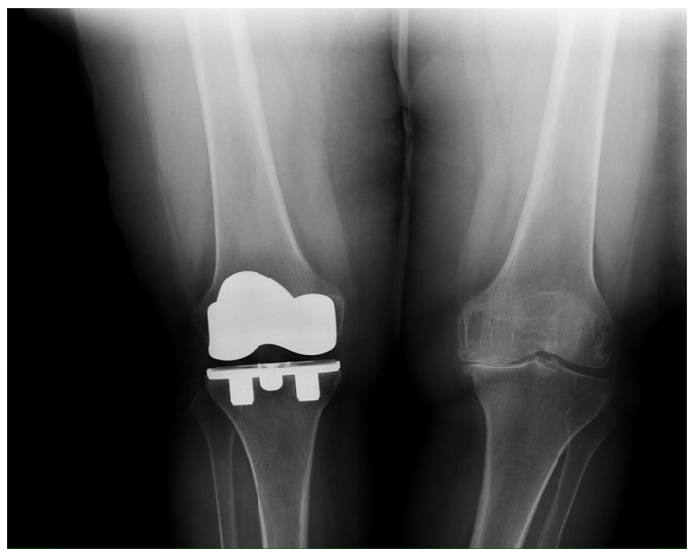

Fig. (10). Radiograph of a knee implant with a trabecular metal tibial component.

\section{CONFLICT OF INTERESTS}

None declared.

\section{ACKNOWLEDGEMENT}

None declared.

\section{REFERENCES}

[1] Gillespie GN, Proteus AJ. Obesity and knee arthroplasty. The Knee 2007; 14: 81-6.

[2] WHO. Obesity: preventing and managing the global epidemic. Geneva: World Health Organization 2000

[3] IASO. International Association for the Study of Obesity, London October 2009.

[4] García-Alvarez A, Serra-Majem L, Ribas-Barba L, et al. Obesity and overweight trends in Catalonia, Spain (1992-2003): gender and socio-economic determinants. Public Health Nutr 2007; 10: 136878.

[5] Felson DT, Anderson JJ, Maunmark A, Walker AM, Meenan RF Obesity and knee osteoarthritis. The Framingham study. Ann Intern Med 1988; 109: 18-24

[6] Powell A, Teichtahl AJ, Wluka AE, Cicuttini FM. Obesity: a preventable risk factor for large joint osteoarthritis which may act through biomechanical factors. Br J Sports Med 2005; 39: 4-5.

[7] Nevitt MC. Obesity outcomes in disease management: Clinical outcomes for osteoarthritis. Obes Res 2002; 10: 33-7.

[8] Spector TD, Hart DJ, Doyle DV. Incidence and progression of osteoarthritis in women with unilateral knee disease in the general population: the effect of obesity. Ann Rheum Dis 1994; 53: 565-8.

[9] Grinker JA, Tucker KL, Vokonas PS, Rush D. Changes in patterns of fatness in adult men in relation to serum indices of cardiovascular risk: the normative aging study. Int $\mathbf{J}$ Obes Relat Metab Disord 2000; 24: 1369-78. 
[10] Hochberg MC, Lethbridge-Cejku M, Scott WW Jr, Reichle R, Plato CC, Tobin JD. The association of body weight, body fatness and body fat distribution with osteoarthritis of the knee: data from the Baltimore Longitudinal Study of Aging. J Rheumatol 1995; 22: 488-93.

[11] Teichtahl AJ, Wluka AE, Wang Y, et al. Obesity and adiposity are associated with the rate of patella cartilage volume loss over 2 years in adults without knee osteoarthritis. Ann Rheum Dis 2009; 68: 909-13.

[12] Ding Ch, Cicuttini F, Scott F, Cooley H, Jones G. Knee structural alteration and BMI: a cross-sectional styudy. Obes Res 2005; 13: 350-1.

[13] Buchholz AL, Niesen MC, Gausden EB, et al. Metabolic activity of osteoarthritic knees correlates with BMI. Knee 2010; 17: 161-6.

[14] Wang Y, Wluka AE, English DR, et al. Body composition and knee cartilage properties in healthy, community-based adults. Ann Rheum Dis 2007; 66: 1244-8.

[15] Dumond H, Presle N, Terlain B, et al. Evidence for a key role of leptin in osteoarthritis. Arthritis Rheum 2003; 48: 3118-29.

[16] Miller GD, Nicklas BJ, Davis CC, Ambrosius WT, Loeser RF, Messier SP. Is serum leptin related to physical function and is it modifiable through weight loss and exercise in older adults with knee osteoarthritis? Int J Obes Relat Metab Disord 2004; 28: 138390 .

[17] Teichtahl AJ, Wluka AE, Proietto J, Cicuttini FM. Obesity and the female sex, risk factors for knee osteoarthritis that may be attributable to systemic or local leptin biosynthesis and its cellular effects. Med Hypotheses 2005; 65: 312-5.

[18] Ding C, Parameswaran V, Cicuttini F, et al. Association between leptin, body composition, sex and knee cartilage morphology in older adults: the Tasmanian older adult cohort (TASOAC) study. Ann Rheum Dis 2008; 67: 1256-61.

[19] Magliano M. Obesity and Arthritis. Menopause Int 2008; 14:14954.

[20] Bao JP, Chen WP, Feng J, Hu PF, Shi ZL, Wu LD. Leptine plays a catabolic role on articular cartilage. Mol Biol Rep 2009; 37(7): 3265-72

[21] Mutabaruka MS, Aoulad AM, Delalandre A, Lavigne M, Lajeunesse D. Local leptin production in osteoarthritis subchondral osteoblasts may be responsible for their abnormal phenotypic expression. Arthritis Res Ther 2010; 12: R20.

[22] Focht BC, Rejeski WJ, Ambrosius WT, Katula JA, Messier SP. Exercise, self-efficacy, and mobility performance in overweight and obese older adults with knee osteoarthritis. Arthritis Rheum 2005; 53: 659-65.

[23] Messier SP, Loeser RF, Miller GD, et al. Exercise and dietary weight loss in overweight and obese older adults with knee osteoarthritis: the arthritis, diet, and activity promotion trial. Arthritis Rheum 2004; 50: 1501-10.

[24] Bliddal H, Christensen R. The management of osteoarthritis in the obese patient: practical considerations and guidelines for therapy. Obes Rev 2006; 7: 323-31.

[25] Messier SP, Gutekunst DJ, Davis C, DeVita P. Weight loss reduces knee-joint loads in overweight and obese older adults with knee osteoarthritis. Arthritis Rheum 2005; 52: 2026-32.

[26] Martin K, Fontaine KR, Nicklas BJ, Dennis KE, Goldberg AP, Hochberg MC. Weight loss and exercise walking reduce pain and improve physical functioning in overweight postmenopausal women with knee osteoarthritis. J Clin Rheumatol 2001; 7: 219-23.

[27] Coggon D, Reading I, Croft P, McLaren M, Barrett D, Cooper C. Knee osteoarthritis and obesity. Int J Obes Relat Metab Disord 2001; 25: 622-7.

[28] Bourne R, Mukhi S, Zhu N, Keresteci M, Marin M. Role of obesity on the risk for total hip or knee arthroplasty. Clin Orthop Relat Res 2007; 465: 185-8.

[29] Liu B, Balkwill A, Banks E, Cooper C, Green J, Beral V. Relationship of height, weight and body mass index to the risk of hip and knee replacements in middle-aged women. Rheumatology (Oxford) 2007; 46: 861-7.

[30] Changulani M, Kalairajah Y, Peel T, Field RE. Relationship between obesity and the age at which hip and knee replacement is undertaken. J Bone Joint Surg Br 2008; 90: 360-3.

[31] Fehring TK, Odum SM, Griffin WL, Mason JB, McCoy TH. The obesity epidemic. Its effect on total joint arthroplasty. J Arthroplasty 2007; 22(6 Suppl 2): 71-6.
[32] Ingrande J, Brodsky JB, Lemmens HJM. Regional anesthesia and obesity. Curr Opin Anaesthesiol 2009; 22: 683-6.

[33] Lee JB, Winstead PS, Cook AM. Pharmacokinetic alterations in obesity. Orthopedics 2006; 29: 984-88.

[34] Miric A, Lom M, Kahn B, Rozenthal T, Bombick D, Sculco TP. Perioperative morbidity following total knee arthroplasty among obese patients. J Knee Surg 2002; 15: 77-83.

[35] Namba RS, Paxton L, Fithian DC, Stone ML. Obesity and perioperative morbidity in total hip and total knee arthroplasty patients. J Arthroplasty 2005; 20 (7 (Suppl 3): 46-50.

[36] Núñez M, Lozano L, Núñez E, Sastre S, Luis Del Val J, Suso S. Good quality of life in severely obese total knee replacement patients: a case-control study. Obes Surg 2011; 21: 1203-8.

[37] Winiarsky R, Barth P, Lotke P. Total knee arthroplasty in morbidly obese patients. J Bone Joint Surg Am 1998; 80: 1770-4.

[38] Krushell RJ, Fingeroth RJ. Primary total knee arthroplasty in morbidly obese patients: a 5- to 14-year follow-up study. J Arthroplasty 2007; 22(6 Suppl 2): 77-80.

[39] Lozano L, Segur JM, Maculé F, et al. Intramedullary versus extramedullary tibial cutting guide in severely obese patients undergoing total knee replacement. Randomized study of 70 patients with Body Mass Index $>35 \mathrm{~kg} / \mathrm{m}^{2}$. Obes Surg 2008; 18(12): 1599-604.

[40] Lozano L, Núñez M, Segur JM, et al. Relationship between knee anthropometry and surgical time in total knee arthroplasty in severely morbidly obese patients. A new prognostic index of surgical difficulty. Obes Surg 2008; 18: 1149-53.

[41] Nuñez M, Lozano L, Nuñez E, Segur JM, Sastre S. Factors influencing health-related quality of life after tka in patients who are obese. Clin Orthop Relat Res 2011; 469: 1148-53.

[42] Patel AD, Albrizio M. Relationship of body mass index to early complications in knee replacement surgery. Arch Orthop Trauma Surg 2008; 128: 5-9.

[43] Chesney D, Sales J, Elton R, Brenkel IJ. Infection after knee arthroplasty a prospective study of 1509 cases. J Arthroplasty 2008; 23: 355-9.

[44] Pulido L, Ghanem E, Joshi A, Purtill JJ, Parvizi J. Periprosthetic joint infection: the incidence, timing, and predisposing factors. Clin Orthop Relat Res 2008; 466: 1710-5.

[45] Bordini B, Stea S, Cremonini S, Viceconti M, De Palma R, Toni A. Relationship between obesity and early failure of total knee prostheses. BMC Musculoskelet Disord 2009; 10: 29.

[46] Jämsen E, Varonen M, Huhtala H, et al. Incidence of prosthetic joint infections after primary knee arthroplasty. J Arthroplasty 2010; 25: 87-92.

[47] Dowsey MM, Choong PF. Obese diabetic patients are at substantial risk for deep infection after primary TKA. Clin Orthop Relat Res 2009; 467: 1577-81.

[48] Malinzak RA, Ritter MA, Berend ME, Meding JB, Olberding EM, Davis KE. Morbidly obese, diabetic, younger, and unilateral joint arthroplasty patients have elevated total joint arthroplasty infection rates. J Arthroplasty 2009; 24(6 Suppl): 84-8.

[49] Stickles B, Philips L, Brox WT, Owens B, Lanzer WL. Defining the relationship between obesity and total joint arthroplasty. Obes Res 2001; 9: 219-23.

[50] Spicer DDM, Pomeroy DL, Badenhausen WE, et al. Body mass index as a predictor of outcome in total knee replacement. Int Orthop 2001; 25: 246-9.

[51] Amin AK, Patton JT, Cook RE, Brenkel IJ. Does obesity influence the clinical outcome at five years following total knee replacement for osteoarthritis? J Bone Joint Surg 2006; 88B: 335-40.

[52] Foran JRH, Michael AM, Etienne G, Jones LC, Hungerford S. The outcome of total knee arthroplasty in obese patients. J Bone Joint Surg 2004; 86A: 1609-15.

[53] Foran JRH, Mont MA, Rajadhyaksha AD, Jones LC, Etienne G, Hungerford S. Total knee arthroplasty in obese group. J Arthroplasty 2004; 19: 817-24.

[54] Vaishnav R, Robert BB, Bert MC, MacDonald SJ, McCalden RW, Rorabeck $\mathrm{CH}$. The impact of morbid obesity on patient outcomes after total knee arthroplasty. J Arthroplasty 2008; 23: 795-800.

[55] Núñez M, Núñez E, del Val JL. Health-related quality of life and costs in patients with osteoarthritis on waiting list for total knee replacement. Osteoarthritis Cartilage 2007, 15: 1001-7.

[56] Núñez M, Lozano L, Núñez E, et al. Total knee replacement and health-related quality of life: factors influencing long-term outcomes. Arthritis Rheum 2009; 61: 1062-9. 
[57] Vazquez-Vela Johnson G, Worland RL, Keenan J, Norambuena N. Patient demographics as a predictor of the ten-year survival rate in primary total knee replacement. J Bone Joint Surg Br 2003; 85(1): 52-6.

[58] Jackson MP, Sexton SA, Walter WL, Walter WK, Zicat BA. The impact of obesity on mid-term outcome of cementless total knee replacement. J Bone Joint Surg 2009; 91-B: 1044-8.

[59] Booth RE. Total knee arthroplasty in the obese patient: tips and quips. J Arthroplasty 2002; 17(suppl 1): 69-0.

[60] Heisel C, Silva M, de la Rosa MA, Schmalzried TP. The effects of lower-extremity total joint replacement for arthritis on obesity. Orthopedics 2005; 28: 157-79.
[61] Lachiewicz AM, Lachiewicz PF. Weight and activity change in overweight and obese patients after primary total knee arthroplasty. J Arthroplasty 2008; 23: 33-40.

[62] Dowsey MM, Liew D, Stoney JD, Choong PF. The impact of preoperative obesity on weight change and outcome in total knee replacement. A prospective study of 529 consecutive patients. J Bone Joint Surg (Br) 2010; 92-B: 513-20.

[63] Andrew LF, Robert CP, Matthew TR. Prevention of venous thromboembolism in obesity. Expert Rev Cardiovasc Ther 2010; 8: 1711-21.

(C) Lozano et al.; Licensee Bentham Open.

This is an open access article licensed under the terms of the Creative Commons Attribution Non-Commercial License (http://creativecommons.org/licenses/by-nc/3.0/) which permits unrestricted, non-commercial use, distribution and reproduction in any medium, provided the work is properly cited. 